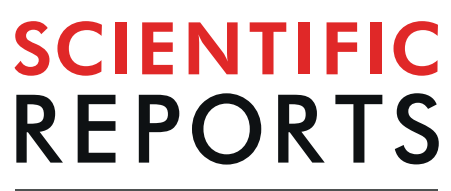

natureresearch

\title{
OPEN Author Correction: Usefulness of peripapillary nerve fiber layer thickness assessed by optical coherence tomography as a biomarker for Alzheimer's disease
}

\author{
Domingo Sánchez, Miguel Castilla-Marti, Octavio Rodríguez-Gómez, Sergi Valero, \\ Albert Piferrer, Gabriel Martínez, Joan Martínez, Judit Serra, Sonia Moreno-Grau, \\ Begoña Hernández-Olasagarre, Itziar De Rojas, Isabel Hernández, Carla Abdelnour, \\ Maitée Rosende-Roca, Liliana Vargas, Ana Mauleón, Miguel A. Santos-Santos, \\ Montserrat Alegret, Gemma Ortega, Ana Espinosa, Alba Pérez-Cordón, Ángela Sanabria, \\ Andrea Ciudin, Rafael Simó, Cristina Hernández, Pablo Villoslada, Agustín Ruiz, Lluís Tàrraga \\ \& Mercè Boada
}

Correction to: Scientific Reports https://doi.org/10.1038/s41598-018-34577-3, published online 05 November 2018

The original HTML and PDF version of this Article contained a typographical error in the spelling of the author Pablo Villoslada, which was incorrectly given as Pablo Villaoslada. This has now been corrected in the HTML and PDF versions of the Article.

\begin{abstract}
(c) (i) Open Access This article is licensed under a Creative Commons Attribution 4.0 International License, which permits use, sharing, adaptation, distribution and reproduction in any medium or format, as long as you give appropriate credit to the original author(s) and the source, provide a link to the Creative Commons license, and indicate if changes were made. The images or other third party material in this article are included in the article's Creative Commons license, unless indicated otherwise in a credit line to the material. If material is not included in the article's Creative Commons license and your intended use is not permitted by statutory regulation or exceeds the permitted use, you will need to obtain permission directly from the copyright holder. To view a copy of this license, visit http://creativecommons.org/licenses/by/4.0/.
\end{abstract}

(C) The Author(s) 2019 